\title{
Evaluation of Public Health Interventions in Shellfish Tag Compliance Rates
}

\author{
Nicole Park ${ }^{1}$, Helen Heacock ${ }^{2}$, Lorraine McIntyre ${ }^{3}$ \\ 1 Lead Author, B. Tech Student, School of Health Sciences, British Columbia Institute of Technology, 3700 Willingdon Ave, \\ Burnaby, BC V5G 3H2 \\ 2 Supervisor, School of Health Sciences, British Columbia Institute of Technology, 3700 Willingdon Ave, Burnaby, BC V5G \\ $3 \mathrm{H} 2$ \\ 3 Contributor, BC Centre for Disease Control, 655 West 12 ${ }^{\text {th }}$ Avenue, Vancouver, BC V5Z 4R4
}

\begin{abstract}
Background: The recent Vibrio parahaemolyticus outbreak in the summer of 2015 highlighted that shellfish tags are one of the key pieces of information used to trace back and determine the source of a foodborne outbreak or illness associated with raw or uncooked shellfish. According to the Canadian Food Inspection Agency, all shellfish tags must meet the requirements stated in the Section 7.3 of the Canadian Shellfish Sanitation Program (CSSP). Non-compliant tags may hinder national and regional regulatory agencies from identifying problems in harvest locations and at the processors, and further impede provincial control measures. As a result of the national outbreak, the BC Center for Disease Control (BCCDC), Ministry of Agriculture and the Canadian Food Inspection Agency (CFIA), as well as health authorities and Environmental Health Officers (EHO) have been involved in a variety of actions and interventions to improve compliance. These include efforts to promote education and to improve control and surveillance of $V$. parahaemolyticus and other shellfish associated illnesses. This study examined the effectiveness of health agencies' interventions to improve shellfish tag compliance rates to Section 7.3 of the CSSP by comparing the numbers of shellfish tags in compliance before and after the interventions that were implemented in 2016.
\end{abstract}

Methods: 120 randomly selected shellfish tags were grouped into "Before" and "After" interventions. By assessing the date of processing, 60 tags collected before September 2016 were placed into the "Before" group. Another 60 tags collected after September 2016 were placed into the "After" group. Within each group, shellfish tags were individually analyzed to determine whether the tag met or exceeded the required quality, information, and type and quantity criteria. Shellfish tags were considered "Compliant" if they completely fulfill 10 components embodied in the criteria, whereas shellfish tags that failed to meet all the components were labeled "Non-compliant".

Results: Based on the statistical analysis conducted on the data, there was a greater proportion of compliant shellfish tags post-intervention compared to pre-intervention. The Pearson's Chi-square test confirmed that there was a statically significant association $(p$-value $=0.000)$ between the numbers of shellfish tags in compliance and the interventions that were implemented after the outbreak.

Conclusion: The results have demonstrated that the interventions implemented by numerous regulatory authorities resulted in greater compliance to Section 7.3 of the CSSP. Public health regulators including the Ministry of Agriculture and the CFIA, as well as BCCDC and EHOs should continuously be involved in a variety of actions, such as promoting education at the processor and retail level and also implementing interventions to improve compliance. By doing so, successful interventions and increased compliance rates will lead to rapid identification of shellfish-related illnesses or outbreaks and facilitate control measures that can expeditiously remediate public health issues.

Keywords: shellfish tag, food traceability, seafood traceability, shellfish processing facility, shellfish biotoxin, food safety, public health 


\section{Introduction}

Vibrio parahaemolyticus is a bacterium naturally found in coastal marine waters worldwide and it causes the most common illnesses associated with ingesting raw or uncooked shellfish (Faber, 2012; Gosling, 2015). Other illnesses associated with ingesting raw shellfish include Hepatitis A, Norovirus, Diarrhetic Shellfish Poisoning, and Paralytic Shellfish Poisoning (BCCDC, 2016; Government of Canada, 2015). During the summer of 2015, Canada experienced the largest $V$. parahaemolyticus outbreak in history. Consumption of raw oysters sourced in $\mathrm{BC}$ were identified as the cause of a total of 73 cultureconfirmed cases and was 2.5 times the number of cases expected. In $\mathrm{BC}$, the control measures were implemented to address the apparent outbreak and public health and food safety investigations were conducted to identify the harvest area (BCCDC, 2015; PHAC 2015). Due to delay and uncertainty in assessing specific harvest areas, the Vancouver Coastal Health Authority ordered to ban the sale of raw oysters harvested on Vancouver Island for the first time since 1997 ("BC Raw Oyster Ban", 2015). Public health and regulatory agencies also took action to recall the product and notify the public. As a result of the national outbreak, public health regulators have been involved in many different actions in an effort to promote education, and to improve control and surveillance of $V$. parahaemolyticus.

The recent outbreak renewed concern

for $V$. parahaemolyticus as a serious foodborne threat to public health and raised concerns about the effectiveness of traceability available at that time. The proposed study was introduced by Lorraine McIntyre from the BCCDC who had observed many shellfish tags that do not meet section 7.3 of CSSP during the outbreak of 2015. Non-compliant tags were illegible, damaged, and missing CSSP required information. This can slow down the ability of national and regional regulatory agencies to identify problems in harvest locations and the processors, and further coordinate provincial response. Following the outbreak, an audit of restaurants was conducted by the BCCDC in collaboration with health authorities and EHOs.
Some of the response measures that were brought forward were requesting EHOs and CFIA to communicate and review section 7.3 of CSSP with the processors during the inspection and to send a written letter to all distributors and processors.

The 2015 outbreak highlighted that shellfish tags are one of the key pieces of information used to determine the source of an outbreak or illness. Without stringent tagging protocol, outbreaks can be prolonged (Reich, Lazensky, \& Faris, 2015). For instance, the Federal Drug Agency (FDA) revealed outbreak investigations could be impeded by the failure to enforce adequate record keeping and tagging requirements of the US National Shellfish Sanitation Program (NSSP) (U.S FDA, 2009). Regulating all steps of processing from farm-tofork is important in preventing, controlling, and reducing shellfish-associated outbreaks. However, one stage of interest is to trace-back implicated shellfish to its source at the retail level to processing and harvesting facilities through improved labeling and tagging systems. Therefore, one of the main objective of this paper is to explore literature and legislation addressing the role of shellfish tags in outbreak investigations and the importance of making shellfish traceable on a more specific level. It then identifies gaps, questions, and limitations in research, policy, and knowledge that could be highly relevant towards future public health policy making.

\section{Evidence Review}

\section{Existing Legislation for Shellfish Quality \& Safety}

Canada has an extensive, well-managed shellfish control program that is managed by a combination of federal, provincial and local authorities. Nonetheless, the majority of legislation for shellfish focuses on regulating the commercial and recreational harvesting and processing of shellfish to be sold in the consumer market (BCCDC, 2015; CSSP, 2012). There are a few pieces of legislation that specify the requirement for a proper shellfish tag: The Canadian Shellfish Sanitation Program (CSSP) Manual of Operations (2015) and the US 
National Shellfish Sanitation Program (NSSP). The Canadian Food Retail and Food Services Code (2004) requires retail and restaurants to retain seafood tags on file for a minimum of 90 days. There are government guidelines and manuals, including BCCDC Guidelines for Bivalve Shellfish Safety: Restaurant and Retail Operator Advice (2016), BCCDC Guidelines for Shellfish Harvesting Process from Farm to Retail (2015), and BCCDC Reference Manual of Provincial Fish Inspection for Retail Operations in Stores and Restaurants (2012). However, guidelines, codes and manuals are rules of practice and are not directly enforceable. They provide guidance and serve an educational purpose to the industry and regulatory authorities.

\section{Challenges to Traceability}

According to Section 7.3 of the CSSP (2012), a durable, waterproof tag or label must contain the following information in English or French and in legible and indelible form. They must be affixed to each non-retail packages that are for sale:

- the date of processing

- the most precise description of the location the shellfish were harvested

- the registration number of the processor and the name and address of the processor or for whom it is shipped to

- the type and quantity of shellfish

The federal CSSP requirement of the "most precise description of the location" is somewhat ambiguous. Instead, it should focus on the specific geographic area that the shellfish are harvested. This would include: harvest area and subarea, landfile number (shellfish farm number or commercial fishing license number), name of nearest road or geographic marker for wild harvest, and lot numbers. Compliance for tags to have the harvest area and sub-area is required; however, further identification of the shellfish farm location is not currently enforced.

\section{Specific Geographic Areas}

The purpose of specific geographic areas is two-fold - ensuring that shellfish are harvested in approved areas to reduce the incidence of Paralytic Shellfish Poisoning, Diarrheic Shellfish Poisoning, Neurotoxic Shellfish Poisoning, and assisting investigators in tracing shellfish back to its specific harvest area and optimizing precision in the event of an outbreak. Approved harvesting areas allow for the monitoring of shellfish harvest waters to reduce the impact of increasing global water temperatures, which has been shown to increase incidences of PSP events (Hawkins, 2013; Joo, 2015; Van der Fels-Klerx, 2012).

\section{Shellfish Tag Compliance}

Maintaining adequate records is considered by some industry members to be a burden. This has resulted in various unacceptable practices being encountered by health officials. Degolier (2009) found that 43\% of surveyed food establishments committed violations regarding shellfish tag management. The most common deficiencies were the failure to keep shellfish tags for 90 days and improper storage in the original containers. In addition to these violations, the study found that $32 \%$ of the establishments were receiving oysters in a manner that did not have harvest information that would be necessary for trace-back investigations. At the processing level, tags that are not in the form that meets the intent of the CSSP requirements to provide trace ability on a lot-by-lot basis will stymie follow-up outbreak investigations.

In the event of a food crisis, the ability to access all important information provided by the shellfish tag should allow an efficient traceability system and enable rapid recalls or withdrawals of products (Aung \& Chang, 2014). Consequently, the existing stipulation for information required on the tags need to be more prescriptive and strictly enforced. Moreover, health authorities and inspection agencies should continuously review Section 7.3 of the CSSP with the processors during their inspections and communicate the need to include shellfish farm level information on their tags. Lastly, retailers and restaurants should reject shellfish shipments 
with missing or questionable information listed on their tags.

\section{Strengths and Limitations of the Literature Review}

This literature review addresses current government initiatives to control and regulate the movement of shellfish throughout Canada, including current protocols for traceability which unfortunately are limited at best. It identifies the primary gaps that could impede traceability in the event of an outbreak, such as the lack of proper shellfish tagging. The importance of shellfish tagging has been undermined by other factors and technologies such as molecular trace-back. For instance, molecular methods rely on the analysis of proteins and/or DNA sequences using polymerase chain reaction (PCR) based methods. PCR is a well-established molecular tool that involves the amplification of DNA segments using specific or arbitrary primers to generate numerous copies of a particular DNA sequence (Badia-Melis, 2015; Leal, 2015). It is used to identify pathogens associated with seafood. Chemical compounds (i.e., fatty acids, protein expression) and isoenzymes that characterize the particular origin of shellfish or fish are also used to discriminate and verify the origin of seafood (Leal, 2015). Whilst these technologies are useful and effective, this literature review attempts to elucidate that effective shellfish tagging should be classified as an equally important traceability measure that is currently being neglected by regulatory agencies.

As previously mentioned, the majority of the studies focused on management of shellfish by molecular or genetic based traceability systems. Other studies that focused on seafood traceability shows scientific methods that were built on what has been invented before. However, these methods are costly and time-consuming in the event of an outbreak where rapid control measures are essential. Despite all of these technologies, significantly less research was found on ensuring shellfish traceability at the retail and processor level, especially during an outbreak investigation. The majority of the literature available fails to address the need for enhanced shellfish tagging.

Furthermore, many of the studies in this review on seafood traceability and safety systems were conducted in different countries. An important factor to consider is that the current statistics in shellfish associated illnesses and outbreaks may not be accurate because of differences between surveillance programs. There may be an over- or under-estimation of the data when two countries are compared to each other. This is because one country may weigh concerns regarding surveillance system differently and be more sensitive to foodborne disease outbreaks than the other (Mattevi \& Jones, 2016). According to Sioen, Henauw, and Parmentier (2007), countries may also have different socioeconomic norms, standards, and attitudes regarding food safety that need to be considered. Hence, it can be difficult to compare and apply findings from one country to another, especially into Canada's food safety system.

\section{Gaps in Research, Policy, and Knowledge}

Shellfish tags should be at the forefront of traceability in public health protection. However, its role is not being widely recognized within regulatory agencies. When an outbreak of disease attributable to shellfish occurs, information stated in the tags used in concert with records will assist health authorities and other agencies to implement subsequent control measures and prevent further outbreaks.

Existing regulations do not have stringent requirements regarding the information supplied to retail markets and to the consumer. The focus lies in the aim to make shellfish traceable on a more specific level to efficiently and effectively determine the source of shellfish contamination. Furthermore, there is a need to implement a system requiring retail operations (stores and restaurants) to accept shipments of shellfish that contain CSSP compliant tags.

\section{Evidence Review Conclusion}

Through this literature review, there is extensive research on a subset of traceability measures, such as molecular trace-back. Nonetheless, there is a significant lack of regulation on shellfish tagging, which is the 
single most reliable source for delineating the original harvest area. In order to achieve this, shellfish tags need to include information compliant to federal legislation and the most precise geographic location to facilitate the implementation of control measures during outbreak investigations.

The purpose of this project was to examine the effectiveness of health agencies' interventions to improve shellfish tag compliance rates to Section 7.3 of the CCSP by comparing the numbers of shellfish tags in compliance before and after the intervention that was implemented in 2016.

\section{Materials \& Methods}

The independent variable of this study was the efficacy of the interventions implemented by the health authorities and the dependent variable was the number of shellfish tags in compliance. The following are the null and alternative hypothesis for this study:

$H_{0}=\quad$ There is no association between the numbers of shellfish tags in compliance and the intervention. The independent and dependent variables are independent of each other.

$H_{A}=\quad$ There is an association between the number of shellfish tags in compliance and the intervention. The independent and dependent variables are not independent of each other

\section{Materials}

The materials that were used in this study included a personal computer with internet access, Section 7.3 of the CSSP manual, Microsoft Excel, NCSS statistical software, a random number generator and shellfish tags. None of the materials used in this study required any form of calibration.

The personal computer with internet access was used to retrieve Microsoft Word, Excel, NCSS Statistical Software, randomizer program, and to gain access to the CSSP manual. MS Excel was used to conduct descriptive statistical analysis and to generate the raw data. Excel was also used to make a row by column table with all the requirements that were listed in Section 7.3 of the CSSP in the column and the assigned tag numbers listed in the row (Figure 1.1). Furthermore, a random number generator in the Excel program was used to ensure that the shellfish tags were randomly selected (Microsoft Excel, 2015).

The data collected was analyzed by NCSS software, which is a statistical and graphic program that provides a wide range of statistical tests and tools (NCSS, 2016).

The Section 7.3 of the CSSP manual specifies the requirements for proper shellfish tags (CFIA, 2012). The requirements were categorized into quality, information, and type and quantity and made into a criteria chart (Figure 1.1). The quality portion of the criteria included whether tags were durable, waterproof, legible and indelible form. The information component of the criteria included the following:

- the date of processing

- the most precise description of the location the shellfish were harvested

- the registration number of the processor

- the name and address of the processor or for whom it is shipped to

- the type and quantity of shellfish

Figure 1.1 Criteria used to evaluate shellfish tags collected before and after the intervention.

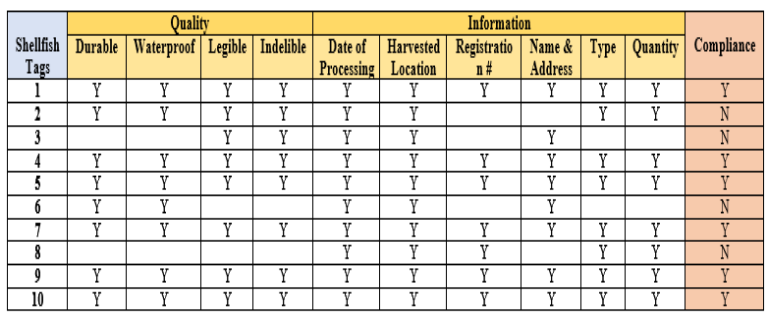

80 shellfish tags were provided by Lorraine Mcintyre from BCCDC. They had been collected by EHOs during visits to restaurants in Greater Vancouver from before and after September 2016. Also, 20 shellfish tags within the total of 80 were directly collected after the interventions from two restaurants located in Burnaby, and one from the downtown region.

\section{Methods}

A total of 80 shellfish tags were grouped into "Before" and "After" intervention. By assessing the date of processing, 40 tags collected before September 2016 were placed 
into the "Before" group and other 40 tags collected after September 2016 were placed into the "After" group. Within each group, tags were randomly assigned a number from 1 to 40 and the order of shellfish tags were produced by the random number generator. From the "Before" group, each shellfish tag was individually analyzed to determine whether the tag met or exceeded the required quality, information, and type and quantity criteria outlined in the table.

Shellfish tags were labelled "Compliant" if they completely fulfilled 10 components embodied in the criteria (Figire 1.1). Whereas, shellfish tags that did not meet all the components were labelled "Non-compliant". The same procedures were performed for the "After" intervention group.

\section{Inclusion \& Exclusion}

The inclusion criteria used in this study included the following sections:

- Required information was in English

- Date of processing was between 2015 to September 2016 and after September 2016

- Location of the processors was within BC

- Tags were collected in restaurants within Greater Vancouver

In contrast, the exclusion criteria included the following sections:

- Required information was in French or in another language

- Location of the processor was outside of BC

- Location of restaurant was outside of Greater Vancouver

\section{Results}

\section{Description of Data}

As the number of shellfish tags could either be in compliance or non-compliance, the observations are considered counts rather than actual measurements, and therefore qualifies as nominal data.

Subsequently, a total of 80 shellfish tags (40 tags in each before and after intervention groups) were summarized into a two-by-two contingency table showing marginal frequencies (Fig. 2.1). Each entry in the table contains the counts of compliant and non-compliant shellfish tags within the before and after intervention groups. In this way, the table can be used to examine the relationships between the two categorical variables. The contingency tables can also be used to depict frequency counts into percentages or ratios (De Veaux, Velleman, \& Bock, 2014) (Fig. 2.2). Overall, in terms of interpreting the data results, the frequency tabulated data allows simpler assessment of differences and similarities between frequency distributions compared to a raw data.

Figure 2.1 Two-way contingency table with marginal frequencies

\begin{tabular}{|c|c|c|c|}
\hline & $\begin{array}{l}\text { Before } \\
\text { Intervention }\end{array}$ & $\begin{array}{l}\text { After } \\
\text { Intervention }\end{array}$ & $\begin{array}{l}\text { Total } \\
(\text { R) }\end{array}$ \\
\hline $\begin{array}{c}\text { Compliant } \\
\text { Tags }\end{array}$ & 14 & 32 & 46 \\
\hline $\begin{array}{c}\text { Non } \\
\text { compliant } \\
\text { Tags }\end{array}$ & 26 & 8 & 34 \\
\hline Total $(\boldsymbol{C})$ & 40 & 40 & 80 \\
\hline
\end{tabular}

Figure 2.2 Two-way relative frequency table showing relative frequencies

\begin{tabular}{|c|c|c|c|}
\hline & $\begin{array}{c}\text { Before } \\
\text { Intervention }\end{array}$ & $\begin{array}{c}\text { After } \\
\text { Intervention }\end{array}$ & $\begin{array}{c}\text { Total } \\
(\boldsymbol{R})\end{array}$ \\
\hline $\begin{array}{c}\text { Compliant } \\
\text { Tags }\end{array}$ & 0.18 & 0.40 & 0.58 \\
\hline $\begin{array}{c}\text { Non } \\
\text { compliant } \\
\text { Tags }\end{array}$ & 0.32 & 0.10 & 0.42 \\
\hline Total $(\boldsymbol{C})$ & 0.5 & 0.5 & 1.00 \\
\hline
\end{tabular}

\section{Descriptive Statistics}

Categorical data can be interpreted using a bar chart or a pie chart. When the pie chart is appropriately designed, it is an effective way of presenting and summarizing large data sets used in this study, especially if the intent is to achieve a quick impression of how a whole group is partitioned into smaller groups. Furthermore, the pie chart provides a visualization check of the reasonableness or accuracy of calculations and comparison between the groups that need to be considered (Heacock, 2016; Falk, Marohn, \& Tewes, 2002).

According to the pie graph (Fig. 2.3), the proportion of shellfish tags that were in compliance before the intervention was 35\% and tags that were in non-compliance was $65 \%$. On the contrary, $80 \%$ of compliant tags and $20 \%$ of non-compliant tags were observed after the 
intervention. The result depicted that the percentage of compliance has increased more than two fold after the intervention.

Figure 2.3 Percentage of compliance and noncompliance between before and after the intervention

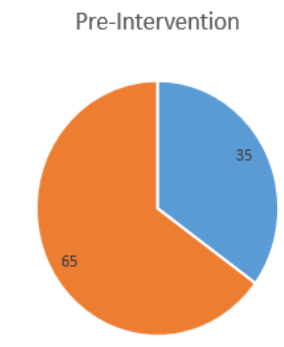

- Compliance - Non-Compliance
Post-Intervention

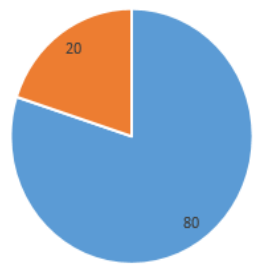

- Compliance = Non-Compliance

\section{Inferential Statistics}

The Chi-square test of independence was appropriate for this research study because the observations were nominal data. The statistical hypothesis test compares frequencies or proportions of compliant and non-compliant shellfish tags between before and after the intervention. A test of independence was performed as the two categorical variables were independent from each other and the occurrence of having compliant or non-compliant shellfish tags did not influence the probability of the next shellfish tag. The independent variable of the study was the efficacy of the interventions implemented by the health authorities and the dependent variable was the number of shellfish tags in compliance to Section 7.3 of the CSSP.

The Chi-square test compares the observed frequency in each cell with the expected frequency. If no relationship exists between the two categorical variables, the observed frequencies will be very close to the expected frequencies. In this instance, a small value of the chi-square statistic will be observed along with a large p-value (Priscilla \& Michael, 1996). On the other hand, the data collected in this study showed that the observed frequencies varied quite a bit from the expected frequencies. This indicated that there was a relationship between the categorical variables and the Chisquare statistic produced a large $\chi^{2}$ value, hence a small p-value (Fig. 2.4) (De Veaux et al., 2014).
The data collected was inputted into MS Excel and then was formatted into two columns for NCSS statistical analysis.

Figure 2.4

Calculated expected frequencies for each cell and comparing with observed frequencies

\begin{tabular}{|c|c|c|c|c|c|}
\hline & \multicolumn{2}{|c|}{$\begin{array}{c}\text { Before } \\
\text { Intervention }\end{array}$} & \multicolumn{2}{|c|}{$\begin{array}{c}\text { After } \\
\text { Intervention }\end{array}$} & \multirow{2}{*}{$\begin{array}{l}\text { Tot } \\
\text { al } \\
\text { (R) }\end{array}$} \\
\hline & $\begin{array}{c}\text { Observ } \\
\text { ed }\end{array}$ & $\begin{array}{l}\text { Expect } \\
\text { ed }\end{array}$ & $\begin{array}{c}\text { Observ } \\
\text { ed }\end{array}$ & $\begin{array}{l}\text { Expect } \\
\text { ed }\end{array}$ & \\
\hline $\begin{array}{l}\text { Compli } \\
\text { ant } \\
\text { Tags }\end{array}$ & 14 & 23 & 32 & 23 & 46 \\
\hline 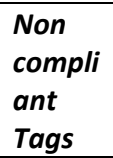 & 26 & 17 & 8 & 17 & 34 \\
\hline $\begin{array}{l}\text { Total } \\
\text { (C) }\end{array}$ & \multicolumn{2}{|c|}{40} & \multicolumn{2}{|c|}{40} & 80 \\
\hline
\end{tabular}

The result supports the claim that there is an association between the two categorical variables. In fact, there was a greater proportion of compliant shellfish tags after the interventions were implemented than when there were none. Since the p-value was found to be 0.000 , the null hypothesis of independence was rejected and the study concluded that there was a statistically significant association between the numbers of shellfish tags in compliance and the interventions that were implemented by numerous regulatory authorities after the outbreak.

\section{Discussion}

As depicted in the results section above, there was a statistically significant association ( $p$-value $=0.000)$ between the numbers of shellfish tags in compliance and the interventions that were implemented by CFIA, Ministry of Agriculture and BCCDC after the 2015 outbreak. After the intervention, the proportion of compliance has increased more than two-fold, however, $20 \%$ of non-compliant tags were still observed at the restaurant level.

\section{Pre-intervention Shellfish Tags}

Prior to September 2016, 62.5\% $(\mathrm{n}=26)$ of shellfish tags failed to meet the requirements listed in Section 7.3 of the CSSP. Generally, paper quality itself was not a prominent issue as 
the majority of the shellfish tags had the required information printed on a durable and waterproof material. However, the writings that were either typed in or hand-written faded were illegible and impermanent. About $43 \%$ of shellfish tags that failed to meet the quality criteria further failed to meet the information component of the CSSP. As a result, it will be difficult to identify and analyze the required information, such as the date of processing, harvested location, registration number, name and address, and type and quantity during the traceback system. Furthermore, $18 \%$ of the shellfish tags were made with a thin, flexible, and permanent adhesive material. Some of these tags were found crumbled during storage, and the adhesive side was easily peeled-off, further damaging other tags.

Most importantly, the biggest issue was observing "illegitimate" shellfish tags that failed to meet all of the ten components embodied in the criteria made in accordance to Section 7.3 of the CSSP. About $10 \%$ of illegitimate tags were found hand-written and hence considered illegible. Also, the required information concerning the identity of the processor, the harvested area, the date of processing, the registration number and the type and quantity of shellfish were completely missing. There should be grounds where shellfish without a proper source of information should not be accepted at either processor, distributor or retail level to prevent the distribution of illegitimate tags. A potential way to prevent fraud would be to educate restaurant operators and employees about what illegitimate tags look like and the importance of refusing to accept them.

\section{Post-intervention Shellfish Tags}

The results have demonstrated that the interventions implemented by numerous regulatory authorities led to greater compliance to Section 7.3 of the CSSP.

Although the proportion of compliance have increased more than two-fold after the intervention, $20 \%$ of non-compliant tags were observed at the processor and restaurant level. About $80 \%$ of the shellfish tags received at the restaurant level included all of the required components listed in the information portion of
Section 7.3 of the CSSP. However, $15 \%$ of the non-compliant tags had information that was faded due to the impermanent ink used by the processors. There were no faulty shellfish tags after the post-intervention.

The recent norovirus outbreak highlights that the shellfish tags are one of the key pieces of information used to determine the source of an outbreak. Since early December 2016, a total of 289 clinical cases of acute gastrointestinal illness associated with the consumption of raw or undercooked oysters have been reported to health authorities in British Columbia (BC), Ontario and Alberta. As a result of the outbreak, four shellfish farms where oysters were harvested in $\mathrm{BC}$ have been closed. The investigation into the cause of the contamination is ongoing as the illness continues to occur and the Public Health Agency of Canada (PHAC), Health Canada, and CFIA are taking collaborative steps to address the outbreak (Public Health Agency of Canada, 2017). Therefore, the focus lies in the aim to make shellfish traceable on a more specific level to efficiently and effectively determine the source of shellfish contamination. Also, the increase in the number of compliant shellfish tags can speed up the ability of national and regional regulatory agencies to identify problems in harvest locations and processing plants, and further coordinate provincial response.

\section{Recommendations}

The increase in the compliance rate to Section 7.3 of the CSSP indicates that the interventions and education made at the processor level were successful. However, further improvements in quality and the information present in the shellfish tags should be considered to allow rapid identification of shellfish-related illnesses or outbreaks during the traceback investigation conducted by the health authorities and public health agencies.

The federal CSSP requirement of the "most precise description of the location" is ambiguous. Instead, it should focus on the specific geographic area in which the shellfish are harvested. This would include the harvest area and subarea, landfile number (shellfish farm number or commercial fishing license number), 
the name of the nearest road or geographic marker for wild harvest, and lot numbers. For instance, the BCCDC highly recommends the landfile number especially during their traceback system. Shellfish tags are required to have the harvest area and sub-area to be compliant; however, further identification of the shellfish farm location is not currently enforced.

The size of the tags can be one of the important factors contributing to the traceback system. Small tags are more likely to be lost during the distribution of the product and can be less visible at a retail point. There are jurisdictions in the United States that impose certain limits. For instance, at least $6.7 \mathrm{~cm} \mathrm{x}$ $13.3 \mathrm{~cm}$ is required in Connecticut as a minimum size for the shellfish tags (U.S. FDA, 2009). Thus, there is a need for standardizing the minimum size of shellfish tags.

Moreover, the order of the information listed on the tags should be consistent. Various headings were given to the same descriptor for the processing date, harvested location, and registration number. For instance, the date of processing outlined in Section 7.3 of the CSSP was represented as packing, shipping or delivery date by various processors. Also, the headings such as original versus final harvest date were misleading.

The shellfish tags that came from the same processor were generally consistent in terms of the material, design, size, and layout and information headings. However, a few variations in the layout of the information and the headings used in the shellfish tags were observed within the processors. Therefore, using a standardized placement of information and terminology may help to speed up the traceback investigation procedures conducted by the health authorities and public health agencies during the outbreak.

Ideally, all the information presented on the tags should be printed. Shellfish tags that require the information to be circled or filled in should be discontinued as the key information can be washed out and become illegible during transport and storage at the retail level.

Maintaining adequate records is considered by some industry members to be a burden. This has resulted in various unacceptable practices being encountered by health officials. Shellfish tags obtained at the restaurant level had no written records of purchase, lack of valuable information on shellfish tags, and were maintained in an unordered manner. Degolier (2009) found that $43 \%$ of surveyed food establishments committed violations regarding shellfish tag management. The most common deficiencies were the failure to keep shellfish tags for 90 days and improper storage in the original containers. In addition to these violations, the study found that $32 \%$ of the establishments were receiving oysters in a manner that did not have the harvest information that would be necessary for trace-back investigations.

The study shows that there is a need to implement a system requiring retail operations (stores and restaurants) to accept shipments of shellfish that contain CSSP compliant tags and reject batches with missing or questionable information listed on their tags. Public health authorities and inspection agencies should continuously investigate the types of shellfish tags restaurants and retails receive with shellfish shipments, as well as the information (i.e. customer receipts containing shellfish-specific information) that restaurants and retails levels could provide during traceback investigations. By doing so, the information collected can be assessed for its usefulness and recommendations can be made for the improvement of shellfish tag quality and information to the CFIA for further implementation at the processor level.

Moreover, health authorities and inspection agencies should continuously review Section 7.3 of the CSSP with the processors during their inspections and communicate the need to include shellfish farm level information on their tags. Lastly, retailers and restaurants should reject shellfish shipments with missing or questionable information listed on their tags.

\section{Limitations}

Although the study has reached its aims, there were some unavoidable limitations. First, because of the time limit, this research was conducted using only a small sample size of shellfish tags. Second, since the shellfish tags were obtained from restaurants located in 
downtown and Burnaby, this may not be indicative of all of Metro Vancouver. Third, the study included shellfish tags that were created by the processors within $\mathrm{BC}$ and with a limited range of processing times. Since it is possible that the compliance results after the interventions may be under- or overrepresented, the relationship from the results may not be extrapolated to larger and more general measures, locations and times. The study should have increased the sample size, collected shellfish tags from various existing processors and from diverse geographic regions with different ranges of processing times to obtain a representative sample that can be generalized across the province.

\section{Future Research}

In the future, student research studies may want to consider the following:

- Compare the number of shellfish tags in compliance after the implementation of interventions in 2017. Some of the response measures that can be brought forward are requesting EHOs and CFIA to continuously communicate and review section 7.3 of CSSP with the processors during the inspection and to send a written reminder letter to all distributors and processors.

- Determine the number of shellfish tags with the landfile number.

- Analyze the number of compliant shellfish tags collected outside of Greater Vancouver.

\section{Conclusions}

The purpose of this project was to examine the effectiveness of health agencies' interventions in improving shellfish tag compliance rates to Section 7.3 of the CSSP by comparing the numbers of shellfish tags in compliance before and after the 2016 intervention.

Examination of the results concluded that the $85 \%$ of the pre-intervention shellfish tags had required information printed on a durable and waterproof material. However, the writings that were either typed in or handwritten faded to be considered illegible and indelible and further failed to meet the information component of the CSSP.

Although the proportion of compliance has increased more than two-fold after the intervention, $20 \%$ of non-compliant tags were observed at the processor and restaurant level. About $85 \%$ of the shellfish tags received at the restaurant level included all of the required components listed in the information portion of Section 7.3 of the CSSP. However, $15 \%$ of the non-compliant tags had information that was faded due to the impermanent ink used by the processors. There were no faulty shellfish tags after the post-intervention.

The results have demonstrated that the interventions implemented by numerous regulatory authorities resulted in greater compliance to Section 7.3 of the CSSP. Public health regulators including the Ministry of Agriculture and the CFIA, as well as BCCDC and EHOs should continuously be involved in a variety of actions, such as promoting education at the processor and retail level and also implementing interventions to improve compliance. By doing so, successful interventions and increased compliance rates will lead to rapid identification of shellfishrelated illnesses or outbreaks and facilitate control measures that can expeditiously remediate public health issues.

\section{Acknowledgements}

This research study was only possible with the help of the BCCDC. Firstly, I would like to thank Lorraine McIntyre for originally contributing the idea as well as her assistance with the project. I would also like to thank Helen Heacock for her continuous help as the supervisor of the project and for the countless hours of editing my papers.

\section{Competing Interests}

The authors declare that they have no competing interests. 


\section{References}

Aung, M.M., \& Chang, Y.S. (2014).

Traceability in a food supply chain: Safety and quality perspectives. Food Control, 39:172-84. Retrieved from http://www.sciencedirect.com/science/ article/pii/S0956713513005811

Badia-Melis, R., Mishra, P., \& Ruiz-García, L. (2015). Food traceability: New trends and recent advances. Food Control, 57:393-401. Retrieved from http://www.sciencedirect.com/science/ar ticle/ pii/S0956713513005811

BC Centre for Disease Control. (2016). Guidelines for Bivalve Shellfish Safety: Restaurant and Retail Operator Advice. Retrieved from http://www.bccdc.ca/resourcegallery/Documents/ Educational\% 20Materials/ EH/FPS/Fish/

Bivalve\%20Safety\%20for\%20RestRetail.pdf

BC Centre for Disease Control. (2015). Guidelines for shellfish harvesting process from farm to retail. Retrieved from http://www.bccdc.ca/resourcegallery/Do cuments/Educational $\% 20$ Materials/EH/FPS/Fish/3_Vp\%20proces s\%20flow_V6\%20Nov\% $\% 2030 \% 202015$. pdf

BC Centre for Disease Control. (2015). Ongoing warm weather increases risk of illness assocatied with raw shellfish consumption. Retrieved from http://www.bccdc.ca/about/newsstories/news-releases/2015/ongoingwarm-weather-increases-risk-of-illnessassociated-with-raw-shellfishconsumption

BC Centre for Disease Control. (2012). Retail operations in stores and restaurants. Retrieved from http://www.bccdc.ca/NR/rdonlyres/52C
4C365-029C-4042-9E9A

0DF7739041EE/ 0/Prov Fish Insp Man _Sec5.pdf

B.C. raw oyster ban lifted by Vancouver Coastal Health (2015, September 17), CBC

News. Retrieved from http://www.cbc.ca/news/canada/britishcolumbia/b-c-raw-oyster-ban-lifted-byvancouver-coastal-health-1.3232563

Canadian Food Inspection Agency. (2012). Canadian Shellfish Sanitation Program. Manual of operations. Retrieved from http://www.inspection.gc.ca/food/fishand-seafood/manuals/canadian-shellfishsanitationprogram/eng/1351609988326/13516105 79883

Canadian Food Inspection System Implementation Group. (2004). Food retail and food services code. Retrieved from http://foodsafe.ca/resources/ Food Services_Code2004.pdf

Degolier, L., Ledin, K., \& Vargulich, G. (2009). Assessment of shellfish practices in licensed retail food establishment in response to increased vibrio illnesses in a landlocked area. J Environ Health, 72(3), 24-7. Retrieved from https://www.ncbi.nlm.nih.gov/pubmed/1 9882988

De Veaux, R., Velleman, P., \& Bock, D. (2014). Intro Stats $\left(4^{\text {th }}\right.$ ed.) New York, Pearson:Addison-Wesley Press.

Faber, S. (2012). Saxitoxin and the induction of Paralytic Shellfish Poisoning. J Young Investigation, 23(1), 1-7. Retrieved from http://www.jyi.org/issue/saxitoxinand-the-induction-of-paralyticshellfishpoisoning/

Falk, M., Marohn, F., \& Tewes, B. (2002). 
Foundations of statistical analyses and applications. Basel, Switzerland, Birkhäuser Basel

Gosling, E. (2015). Marine bivalve molluscs. Chichester, UK: John Wiley \& Sons Press

Government of Canada. (2015). Vibrio parahaemolyticus. Retrieved from http://www.healthycanadians.gc.ca/eatin g-nutrition/risks-recalls-rappelsrisques/poisoningintoxication/poisoningintoxication/vibrio-eng.php

Hawkins, E., \& Jones, P.D. (2013). On increasing global temperatures: 75 years after Callendar. $Q J R$ Meteorol Soc, 139(677):1961-3. Retrieved from http://onlinelibrary.wiley.com/ doi/10.1002/ qj. 2178/pdf

Heacock, H., Karakilic, V. (2016). Research methods module 5: Inferential Statistics. One Sample T-test, Two Sample T-test, Chi-Square Test, ANOVA, Regression \& Correlation. [PowerPoint Slides]. October 24, 2016.

Joo, Y., You, K., \& Park, K.H. (2015). Prediction of paralytic shellfish toxin based on a projected future climate scenario for South Korea. Food Research Internation, 68:47-53. Retrieved from https://www.researchgate.net/publicatio n/274021073_Prediction_of_paralytic_s hellfish_toxin_based_on_a_projected_fu ture_climate_scenario_for_South_Korea

Leal, M.C., Pimentel, T., \& Ricardo, F. (2015). Seafood traceability: Current needs, available tools, and biotechnological challenges for origin certification. Trends in Biotechnology, 33(6), 331-6. doi: 10.1016/j.tibtech.2015.03.003
Mattevi, M., \& Jones, J.A. (2016). Traceability in the food supply chain: Awareness and attitudes of UK Small and Mediumsized Enterprises. Food Control, 64:120-7. Retrieved from http://www.sciencedirect.com/science/ar ticle/pii/S0956713515303303

Microsoft Excel [Computer software]. (2015). Available from https://www.microsoftstore.com/ store/msca

National Shellfish Sanitation Program. (2011). Guide for the control of molluscan shellfish. Retrieved from http://www.fda.gov/downloads/Food/Gu idanceRegulation/FederalStateFood Programs/ UCM350

NCSS Statistical Software. (2016). Retrieved from https: www.ncss.com/software

Priscilla, E., \& Michael, N. (1996). A guide to chi-squared testing. Wiley Press.

Public Health Agency of Canada. (2015). Outbreak of Vibrio parahaemolyticus linked to raw shellfish. Retrieved from http://www.phac-aspc.gc.ca/phnasp/2015/vibrioparahaemolyticuseng.php

Public Health Agency of Canada (2017). Pubilc Health Notice - Ongoing outbreak of norovirus and gastrointestinal illnesses linked to raw and undercooked oysters from British Columbia. Retreived from http://www.phac-aspc.gc.ca/phnasp/2017/outbreak-norovirus-eclosioneng.php

Reich, A., Lazensky, R., \& Faris, J. (2015). Assessing the impact of shellfish harvesting area closures on neurotoxic shellfish poisoning (NSP) incidence during red tide (Karenia brevis) blooms. Harmful alge. 43:13-9. 
Sioen, I., Henauw, S., \& Parmentier, K. (2007).

Determining the Origin of Seafood

Products on the Belgian Market :

Challenges to Traceability and Database

Management. Open Food Science

Journal, 1(1), 33-42. Retrieved from

https://www.researchgate.net/publicatio n/250143673_Determining_the

Origin_of_Seafood_Products_on_the_B

elgian_Market_Challenges_to_Traceabil

ity_and_Database_Management

U.S. Food and Drug Administration. (2009).

National Shellfish Sanitation Program:

Shellfish tagging. Retrieved from

http://www.issc.org/client_resources/20

09\% 20nssp\%20guide/

section $\% 20 \mathrm{v} \% 20$ chapter\%20iii\%20.04.

pdf

Van der Fels-Klerx, H.J., Olesen, J.E., \&

Naustvoll, L.J. (2012). Climate change impacts on natural toxins in food production systems, exemplified by deoxynivalenol in wheat and diarrhetic shellfish toxins. Food Addit Contam

Part A, 29(10):1647-59. doi:

10.1080/19440049.2012.714080. 